\title{
USE OF INFILTRATIVE ANESTHESIA IN ACUTE ANTERIOR DISLOCATION OF SHOULDER
}

\author{
Murat Koken ${ }^{1} \odot$, Ahmet Hakan Kara $^{2} \odot$ Cem Guneri $^{3} \odot$, Berk Guclu ${ }^{3} \odot$ \\ ${ }^{1}$ Antalya Bilim University, Antalya, Turkey \\ ${ }^{2}$ Akdamar Private Hospital, Van, Turkey \\ ${ }^{3}$ Department of Orthopaedics and Traumatology, Ufuk University Faculty of Medicine, Ankara, Turkey
}

\begin{abstract}
BACKGROUND: To evaluate the results of infiltrative anesthesia for manual closed reduction of acute primary anterior shoulder dislocation.

MATERIAL AND METHODS: A total of 55 adults with acute anterior dislocation of shoulder who were treated with Hippocratic maneuver were evaluated. Infiltrative anesthesia was applied directly to the deltoid muscle from two anatomic locations in anterolateral and posterolateral of the shoulder with prilocaine hydrochloride and bupivacaine (Citanest ${ }^{\circledR}+$ Marcaine $^{\circledR}$ ) was applied to all patients. All patients' reductions were made by the same orthopaedic surgeon. Visual Analog Scale (VAS) of pain was applied to all subjects for evaluating the pain in management after the treatment. Demographic and clinical data, time of duration for reduction, and duration of hospitalization were recorded.
\end{abstract}

RESULTS: Mean age was $57.9 \pm 4.5$ years, $22 \%$ were women. The reduction was completed with the mean duration of $1.0 \pm 0.3$ minutes after applying infiltrative anesthesia. The mean VAS scores of the patients used infiltrative anesthesia were 4.6 which indicated moderate pain. The treatment was completed in the emergency room so that patients could be discharged after reduction in the emergency department. No recurrence and complications were observed in the one-year follow-up period.

CONCLUSION: Our study showed that infiltrative anesthesia, in addition to its easy management by orthopaedic surgeons, allows successful and fast reduction by avoiding difficulties caused by the contraction of the deltoid muscle without necessitating sedoanalgesia or general anesthesia.

KEY WORDS: acute, shoulder dislocation, infiltrative anesthesia, emergency

Disaster Emerg Med J 2021; 6(2): 70-74

\section{INTRODUCTION}

Anterior shoulder dislocations (ASD) are the most frequent emergency consultation reasons for orthopaedic surgeons [1-3]. The selection of the type of anesthesia and analgesia is very important to achieve reduction quickly and without complication. Several studies have reported different anesthesia methods for the reduction of ASD [4-6]. Currently, intra-articular, sedative and intravenous anesthesia methods are used in orthopaedic clinics [4-6]. In our clinic, both of the methods for anesthesia have been used. Infiltration of local anesthetics around the joint as an analgesic adjunct for postoperative joint surgery pain has been used for decades [7-10]. However, there is no evidence in using for the management of ASD.

Also, several reduction methods for manual closed reduction of acute primary ASD have been 
used such as Kocher, traction-countertraction, scapular manipulation, modified Stimson and Hippocratic method to which we used for this study [1-3, 11, 12]. There is no consensus about anesthesia options and reduction methods. This is a very ancient method - as the name suggests - and it has relatively recently been revived as perhaps the safest method of shoulder reduction [11]. The Hippocratic maneuver is preferred in our center due to its educational value. Besides, this safe maneuver can be quickly applied with a limited number of medical staff.

The most important point in choosing the method of anesthesia in ASD reduction is patient comfort achieved by pain management. Anesthesia relaxes the muscular spasm and thus facilitates reduction. The aim is to relocate the shoulder while minimizing the risk of complications. Choosing the right method of anesthesia greatly reduces the incidence of complications. Anesthesia should provide pain control, increase patient comfort and not cause complications. The surgeon should choose a safe method that is easy to administer. A method of anesthesia that does not require the presence of an anesthesiologist shortens the procedure and lowers the cost. The aim of our study was to report the results of infiltrative shoulder anesthesia in manual closed reduction of acute primary ASD.

\section{MATERIAL AND METHODS}

A total of 55 adults with acute ASD aged 38-74 years (43 men and 12 women) were recruited to the study between July 2013-July 2017. All patients who applied with acute primary ASD to the emergency service were evaluated for the study. All patients signed a written consent form. Ethics com- mittee approval was received for this study from the local ethics committee of our institute. 55 patients were included in the study after exclusion of patients who had recurrent ASD, dislocation with fracture, inferior and posterior dislocation of shoulder and patients with alcohol addiction and a history of allergic reactions with local anesthetics.

Infiltrative anesthesia applied with prilocaine hydrochloride 2.5 cc + bupivacaine 2.5 cc (CitanestR + MarcainR) for all patients with the dose of 3-4 mg/kg (maximum single dose not to exceed $500 \mathrm{mg}$ for prilocaine hydrochloride and $2-2.5 \mathrm{mg} / \mathrm{kg}$ (maximum single dose not to exceed $175 \mathrm{mg}$ ) for bupivacaine [13, 14]. Infiltrative anesthesia was applied directly to the deltoid muscle from two anatomic locations in the anterolateral and posterolateral shoulder (Fig. $1 \mathrm{a}-\mathrm{c}$ ). All the patients' shoulders were reduced using the Hippocratic maneuver by the same orthopaedic surgeon. The duration of the reduction and the duration to discharge were recorded by the medical assistants.

Demographic data such as age, gender, smoking and alcohol consumption status, recurrence of ASD was recorded. In addition, VAS was measured to assess the improvement in pain, with a scale of 0 representing no pain and 10 representing extreme pain. The version of VAS used in this study was standardized into Turkish [15]. VAS is a unidimensional measure of pain intensity, which is widely used in diverse adult populations. To rule out memory problems, patients were numbered between 0 to 10 on the questionnaire due to their pain severity in one-hour time after management. VAS was measured 30-60 minutes after reduction.

All the patients were followed with Velpau bandage after reduction for two weeks. The rehabilitation

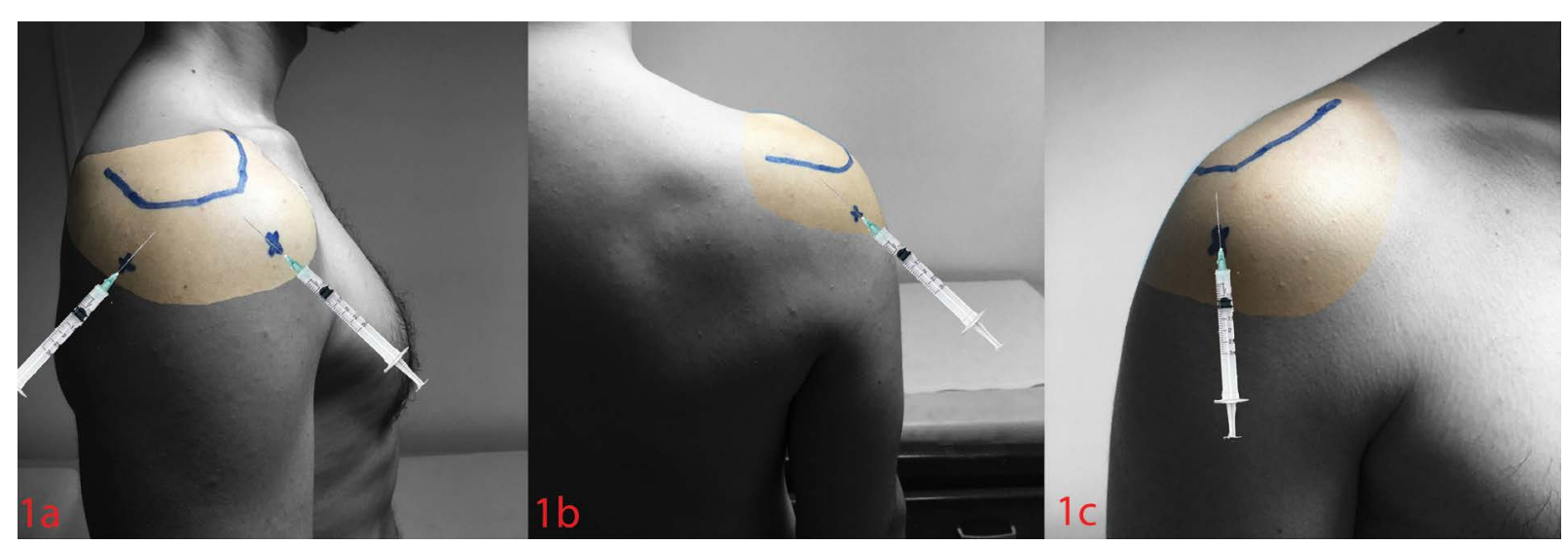

FIGURE 1. Demonstrates the method of performing infiltrative anesthesia procedure; 1a: lateral view, 1b: posterior view, 1c: anterior view 
program was started after the third week from the management to gain a normal range of motion. All patients were reevaluated in the clinic one year following reduction.

Data analyses were performed by using SPSS for Windows, version 22.0 (SPSS Inc., Chicago, IL, United States). Data was described as mean \pm SD and for normal distributions, and categorical data were described as a number of cases (\%).

\section{RESULTS}

The study included 55 patients who applied to the emergency service with acute ASD. Of these, $76 \%$ were men. The mean age of the patients were $57.9 \pm 4.5$ years. Three patients who consumed alcohol reported their consumption as less than once a month and more than three times in a year. None of the patients had a history of alcohol or tobacco consumption. The mean duration of reduction was recorded as $1.0 \pm 0.3$ minutes. Reductions were completed in the emergency room for all patients and none of the patients needed hospitalization. Complications such as fracture or neurovascular damage were not observed. Mean VAS scores of the patients with infiltrative anesthesia were indicated moderate pain. Also, discharge of duration from emergency service after reduction varied between 64.1 minutes to 117.5 minutes. Table 1 summarizes the demographic and clinical data of the patients.

All the patients were evaluated with shoulder MRI in the third week of follow-up. Bankart lesions were detected in 5/55 patients. All five patients with Bankart lesions were elderly patients with sedentary lifestyles and were given conservative treatments for this reason. We choose surgical treatment for patients younger than twenty-five who actively participate in sports and conservative treatment for patients older than forty. Partial rotator cuff tears were detected in 10/55 patients who is older than 54 years old.

All the patients have still been followed up with a normal range of motion in the shoulder after an appropriate rehabilitation program.

\section{DISCUSSION}

The optimal type of analgesia and sedation has been subject to debate for a long time in the literature but limited sample sizes and assessments make choosing difficult. A consensus on the optimal type of analgesia has not been reached in meta-analyses [12].

Some studies intravenous anesthetics such as ketamine, propofol, fentanyl alone or their combinations. Some authors preferred midazolam for sedative anesthesia because of its pharmacological properties. Midazolam is a very useful agent with a rapid onset and short half-life and which results in a rapid offset of effect and faster recovery. But adverse effects such as respiratory depression, drowsiness, vomiting, nausea, headache and hypotension have been reported [16-17]. Prilocaine hydrochloride and bupivacaine were preferred in our study for intra-articular anesthesia although other studies mostly used $1 \%$ lidocaine [12].

Compared to other studies, our success of reduction is very high with a percentage of $100 \%$. Fitch et al reported $89.9 \%$ success with intra-articular anesthesia and $95.6 \%$ success in the patients who received intravenous anesthesia [18]. The success

\begin{tabular}{|c|c|c|c|}
\hline & Infiltrative anesthesia & Intra-venous anesthesia & $P$ value \\
\hline Mean Age & $57.9 \pm 4.5$ & $58,1 \pm 5.1$ & 0.144 \\
\hline Sex ratio & $2 \mathrm{~F} / 18 \mathrm{M}$ & $1 \mathrm{~F} / 14 \mathrm{M}$ & \\
\hline Recurrence of ADS & No & No & \\
\hline Duration of reduction (minutes) & $2.86 \pm 0.85$ & $4.21 \pm 1.15$ & 0.044 \\
\hline Adverse effects & No & $\begin{array}{c}\text { respiratory depression and } \\
\text { hypoxemia in } 2 \text { patients } \\
\text { drowsiness in } 1 \text { patient } \\
\text { nausea in } 1 \text { patient }\end{array}$ & \\
\hline VAS scores & $8.2 \pm 0.9$ & $7.6 \pm 1.2$ & 0.088 \\
\hline Discharge duration (minutes) & $90.8 \pm 26.7$ & $550.6 \pm 180.5$ & 0.014 \\
\hline
\end{tabular}


rates are variable due to time of application for the dislocation, time for reduction after the dislocation and surgeon's level of expertise [19-20].

The effect of anesthesia on pain is an undeniable fact. The main power of our study is the objective measurement of pain scores. Consistent with the literature, lower VAS scores were obtained compared with the other anesthesia methods [21].

The overall duration of reduction and discharge, not surprisingly, was shorter in this study [22-23]. If the measurement of the effectiveness with pain is enough for researchers, this result revealed that cost-effectiveness is higher in infiltrative anesthesia.

Successful reduction without complications is very important for orthopaedic surgeons. Also, the duration of hospitalization and discharge are directly affected by the complications. We observed no complications with infiltrative anesthesia and Hippocratic maneuver. This is one of the most important reasons why we suggest using infiltrative anesthesia. There are frequent reports of nausea, drowsiness and hypoxemia with sedoanalgesia in the literature $[4,24]$.

Duration of hospitalization and discharge are affected by several factors such as dosage of anesthesia, development of complications, technique of reduction, experience of surgeon and medical team. In our study, we found a decreased time of duration for discharge. These results are believed to be related to lower complication rates and the use of the same technique for all patients by the same orthopaedic surgeon.

This study has some limitations. We applied the VAS questionnaire after the reduction that mainly depends on patients' memory. Another limitation is the number of participants and the lack of female patients.

Infiltrative anesthesia allows successful reduction without necessitating sedation or general anesthesia by avoiding deltoid muscle spasm and pain and can easily be applied by orthopaedic surgeons. We were able to carry out reduction in a shorter time with less pain using infiltrative anesthesia. Application of intramuscular anesthesia to the points using doses described in the text has resulted in success in terms of both patient and surgeon comfort. However, due to the low number of patients, these results need to be evaluated in a double-blinded randomized study with larger sample size.

\section{REFERENCES}

1. Dala-Ali B, Penna M, McConnell J, et al. Management of acute anterior shoulder dislocation. Br J Sports Med. 2014; 48(16): 1209-1215, doi: 10.1136/bjsports-2012-091300, indexed in Pubmed: 22821719.

2. Krøner K, Lind T, Jensen J. The epidemiology of shoulder dislocations. Archives of Orthopaedic and Trauma Surgery. 1989; 108(5): 288-290, doi: 10.1007/bf00932317.

3. Goss T. Anterior Glenohumeral Instability. Orthopedics. 1988; 11(1): 87-95, doi: 10.3928/0147-7447-19880101-10.

4. Kosnik J, Shamsa F, Raphael E, et al. Anesthetic methods for reduction of acute shoulder dislocations: a prospective randomized study comparing intraarticular lidocaine with intravenous analgesia and sedation. Am J Emerg Med. 1999; 17(6): 566-570, doi: 10.1016/s0735-6757(99)90197-3, indexed in Pubmed: 10530535.

5. Chung J. The effectiveness of a specially designed shoulder chair for closed reduction of acute shoulder dislocation in the emergency department. http://isrctn.org/>., doi: 10.1186/isrctn49254586.

6. Matthews D, Roberts T. INTRA-ARTICULAR LIDOCAINE VERSUS INTRAVENOUS ANALGESIA FOR REDUCTION OF ACUTE ANTERIOR SHOULDER DISLOCATIONS. Southern Medical Journal. 1993; 86(Supplement): 85, doi: 10.1097/00007611-199309001-00231.

7. McKenzie PJ, Loach AB. Local anaesthesia for orthopaedic surgery. $\mathrm{Br}$ J Anaesth. 1986; 58(7): 779-789, doi: 10.1093/bja/58.7.779, indexed in Pubmed: 3524641.

8. Aranda M. Pain Management and Regional Anesthesia in Trauma. Regional Anesthesia and Pain Medicine. 2000; 25(3): 334, doi: 10.1097/00115550-200005000-00037.

9. Chelly JE, Gebhard R, Greger J, et al. Regional anesthesia for outpatient orthopedic surgery. Minerva Anestesiol. 2001; 67(9 Suppl 1): 227-232, indexed in Pubmed: 11778122.

10. Weinstein EJ, Levene JL, Cohen MS, et al. Local anaesthetics and regional anaesthesia versus conventional analgesia for preventing persistent postoperative pain in adults and children. Cochrane Database Syst Rev. 2018; 4: CD007105, doi: 10.1002/14651858. CD007105.pub3, indexed in Pubmed: 29694674.

11. Alkaduhimi $H$, van der Linde JA, Flipsen $M$, et al. A systematic and technical guide on how to reduce a shoulder dislocation. Turk J Emerg Med. 2016; 16(4): 155-168, doi: 10.1016/j.tjem.2016.09.008, indexed in Pubmed: 27995208.

12. Jiang $\mathrm{N}, \mathrm{Hu} \mathrm{Yj}_{\mathrm{j}}$, Zhang $\mathrm{Kr}$, et al. Intra-articular lidocaine versus intravenous analgesia and sedation for manual closed reduction of acute anterior shoulder dislocation: an updated meta-analysis. J Clin Anesth. 2014; 26(5): 350-359, doi: 10.1016/j.jclinane.2013.12.013, indexed in Pubmed: 25066879.

13. Doral M, Doral M, Turhan E, et al. Endoscopy and Percutaneous Suturing in the Achilles Tendon Ruptures. Sports Injuries. 2011: 917-923, doi: 10.1007/978-3-642-15630-4_118. 
14. Reynolds F. Maximum Recommended Doses of Local Anesthetics. Regional Anesthesia and Pain Medicine. 2005; 30(3): 314-316, doi: 10.1097/00115550-200505000-00024.

15. Yaray 0 , Akesen B, Ocaklioğlu G, et al. Validation of the Turkish version of the visual analog scale spine score in patients with spinal fractures. Acta Orthop Traumatol Turc. 2011; 45(5): 353-358, doi: 10.3944/ A0TT.2011.2528, indexed in Pubmed: 22033000.

16. Moharari RS, Khademhosseini P, Espandar R, et al. Intra-articular lidocaine versus intravenous meperidine/diazepam in anterior shoulder dislocation: a randomised clinical trial. Emerg Med J. 2008; 25(5): 262-264, doi: 10.1136/emj.2007.051060, indexed in Pubmed: 18434457.

17. Orlinsky M, Shon S, Chiang C, et al. Comparative study of intra-articular lidocaine and intravenous meperidine/diazepam for shoulder dislocations. J Emerg Med. 2002; 22(3): 241-245, doi: 10.1016/ s0736-4679(01)00475-9, indexed in Pubmed: 11932085.

18. Fitch RW, Kuhn JE. Intraarticular lidocaine versus intravenous procedural sedation with narcotics and benzodiazepines for reduction of the dislocated shoulder: a systematic review. Acad Emerg Med. 2008; 15(8): 703-708, doi: 10.1111/j.1553-2712.2008.00164.x, indexed in Pubmed: 18783486.

19. Cheok CY, Mohamad JA, Ahmad TS. Pain relief for reduction of acute anterior shoulder dislocations: a prospective randomized study comparing intravenous sedation with intra-articular lidocaine. J Orthop
Trauma. 2011; 25(1): 5-10, doi: 10.1097/BOT.0b013e3181d3d338, indexed in Pubmed: 21164304.

20. Hames H, McLeod S, Millard W. Intra-articular lidocaine versus intravenous sedation for the reduction of anterior shoulder dislocations in the emergency department. CJEM. 2011; 13(6): 378-383, doi: 10.2310/8000.2011.110495, indexed in Pubmed: 22436475.

21. Dunn MJG, Mitchell R, Souza CD, et al. Evaluation of propofol and remifentanil for intravenous sedation for reducing shoulder dislocations in the emergency department. Emerg Med J. 2006; 23(1): 57-58, doi: 10.1136/emj.2004.021410, indexed in Pubmed: 16373806.

22. Hames H, McLeod S, Millard W. Intra-articular lidocaine versus intravenous sedation for the reduction of anterior shoulder dislocations in the emergency department. CJEM. 2011; 13(6): 378-383, doi: 10.2310/8000.2011.110495, indexed in Pubmed: 22436475.

23. Dunn MJG, Mitchell R, Souza CD, et al. Evaluation of propofol and remifentanil for intravenous sedation for reducing shoulder dislocations in the emergency department. Emerg Med J. 2006; 23(1): 57-58, doi: 10.1136/emj.2004.021410, indexed in Pubmed: 16373806.

24. Miller SL, Cleeman E, Auerbach J, et al. Comparison of intra-articular lidocaine and intravenous sedation for reduction of shoulder dislocations: a randomized, prospective study. J Bone Joint Surg Am. 2002; 84(12): 2135-2139, doi: 10.2106/00004623-200212000-00002, indexed in Pubmed: 12473699. 